\title{
Hypertensive disorders in twin pregnancy
}

\author{
Job G. Santema, Inge Koppelaar, Henk C.S. Wallenburg* \\ Institute of Obstetrics and Gynecology, Erasmus University School of Medicine and Health Sciences EE 2283, P.O. Box 1738, \\ 3000 DR Rotterdam, The Netherlands
}

Accepted 4 October 1994

\begin{abstract}
Objective: To compare the incidence and severity of pregnancy-induced hypertensive disorders in twin pregnancy and in singleton gestation. Study design: Case-control study in the setting of a University Hospital. Each pregnancy of a consecutive series of 187 twin pregnancies attending the antenatal clinic and booked before a gestational age of 24 weeks was matched for maternal age, parity, and gestational age at delivery with a singleton pregnancy delivered in the same year. Primary end points of the analysis of the course and outcome of pregnancy were pregnancy-induced hypertension and proteinuric pre-eclampsia. Results: In the twin pregnancy group, $21 \%$ of patients met the criteria for the diagnosis of a pregnancy-induced hypertensive disorder, compared with $13 \%$ in the singleton pregnancy group $(P<0.05)$. The difference was due to a significantly higher incidence of pregnancy-induced hypertension in twin $(15 \%)$ than in singleton $(6 \%)$ pregnancy $(P<0.05)$, in particular in nulliparous women. The incidence of preeclampsia was similar in twin $(6 \%)$ and singleton pregnancies $(6.5 \%)$, without a difference in severity and in the occurrence of the HELLP syndrome. Conclusion: The incidence of non-proteinuric pregnancy-induced hypertension, but not of proteinuric preeclampsia, is increased in twin pregnancy.
\end{abstract}

Keywords: Twin pregnancy; Pregnancy-induced hypertensive disorders; Pre-eclampsia

\section{Introduction}

The majority of published reports on complications of twin pregnancy show an increase in the incidence of hypertensive disorders, which tend to occur earlier and to run a more severe course than in singleton gestation. Incidences of $20-30 \%$ are reported, 3-5 times higher than in singleton pregnancies [1-3]. Unfortunately, the older studies in particular lack adequate control groups and the criteria used to define hypertensive disease vary markedly [3,4-8]. In some cases no distinction is made between pregnancy associated with hypertension already existing before pregnancy and pregnancy-induced hypertensive disorders, with or without proteinuria [4-8]. In addition, many reports do not distinguish between proteinuric pre-eclampsia, with its increased maternal and fetal risks, and non-proteinuric pregnancy-induced hypertension, the main risk of which is the development of pre-eclampsia [9]. A reliable assessment of the risk of pregnancy-induced hypertensive disease in twin pregnancy has become even more rele-

\footnotetext{
* Corresponding author.
}

vant since evidence has become available that a low dose of aspirin may prevent the development of early-onset pre-eclampsia with preterm delivery in pregnancies at high risk $[10,11]$, which could include multiple pregnancy.

The present study was designed to assess the incidence and severity of hypertensive disorders in twin pregnancy in a consecutive series of 187 patients attending the antenatal clinic of the University Hospital RotterdamDijkzigt from early in pregnancy. Strict definitions were applied and the results were compared with those in a control group of an equal number of women with singleton pregnancies, matched for maternal age, parity and gestational age at delivery.

\section{Materials and methods}

All charts of patients with a twin pregnancy delivered in the University Hospital Rotterdam-Dijkzigt during the 10-year period between 1983 and 1992 were reviewed. Of the 447 patients, 187 were booked in our antenatal clinic before a gestational age of 24 weeks and remained under our care until after delivery. The 
remaining 260 patients were referred to our hospital after 24 weeks gestation for various maternal or fetal complications, including hypertensive disorders, and were not included in the study. Each twin pregnancy was matched for parity, maternal age (to within 2 years), and gestational age at delivery (within 1 week) with a singleton pregnancy, under our antenatal care before 24 weeks' gestation and delivered in the same year as the index case. The matching was done by determining in a blinded fashion without knowledge of the course and outcome of pregnancy the first singleton delivery that was registered before or after the birth of a pair of twins and that met all matching criteria.

Primary end points of the analysis of course and outcome of pregnancy in both groups were the occurrence of pregnancy-induced hypertension (PIH) and preeclampsia. Based on the recommendations of the International Society for the Study of Hypertension in Pregnancy [12], PIH was defined as the occurrence after 20 weeks gestation in a previously normotensive woman of a diastolic blood pressure of $90 \mathrm{mmHg}$ or more, determined in sitting position at Korotkoff 4 on two occasions at least $4 \mathrm{~h}$ apart. PIH with proteinuria of $0.3 \mathrm{~g} / 1$ or more in a $24-\mathrm{h}$ urine collection period exclusive of urinary infection or contamination was considered preeclampsia. A diagnosis of the syndrome of hemolysis, elevated liver enzymes, and a low platelet count (HELLP) was made in pre-eclamptic patients with hemolysis in a peripheral smear, serum levels of aspartate aminotransferase (ASAT) and alanine aminotransferase (ALAT) greater than $30 \mathrm{U} /$, and a platelet count of less than $100 \times 10^{9} / 1$. Superimposed pre-eclampsia was defined as proteinuria developing for the first time during pregnancy in a woman with chronic hypertension.

Perinatal mortality was used as a subsidiary end point, and defined as the sum of all fetal deaths with a birthweight of $500 \mathrm{~g}$ or more and neonatal deaths of 500 $\mathrm{g}$ or more within 28 days after birth per 1000 births. We defined the birthweight ratio as the quotient of the actual birthweight of the infant and the expected birthweight on the 50th percentile of the Dutch intrauterine growth curve for singleton pregnancies corrected for gestational age, sex and parity [13]. All twin placentae were macroscopically and histologically examined, but investigations to establish zygosity such as blood group determination or HLA tissue typing were not routinely done. Twin pairs with a monochorionic placenta were classified as certainly monozygotic, and all unlike-sex twin pairs were classified as certainly dizygotic. Based on Weinberg's [14] hypothesis that for every pair of unlike-sex dizygotic twins there will be one like-sex pair, the estimated number of monozygotic twins was calculated by substracting the total number of unlikesex twin pairs from the number of like-sex pairs.

Data are presented as median and range throughout. Differences in continuous variables were assessed with
Wilcoxon's rank sum test for comparison between groups, and discrete data were analysed with the $\chi^{2}$ test. A two-tailed probability level of 0.05 or less was considered to represent statistical significance.

\section{Results}

Clinical characteristics and outcome of the 187 predominantly white women with twin and singleton pregnancies are summarized in Table 1.

Because of the matching criteria used there are no differences with respect to maternal age, parity and gestational age at delivery. We observed no significant difference between twin pregnancies and singleton controls in gestational age at the first antenatal visit, and in cesarean section rate. There are no significant differences between the birthweights of first and second twins; the birthweight ratios of twins are significantly lower than those of singletons $(P<0.05)$.

The incidence of hypertensive disorders in twin and singleton pregnancies is summarized in Table 2. In the twin group $21 \%$ met the criteria for diagnosis of a pregnancy-induced hypertensive disorder, as compared with $13 \%$ in the singleton group $(P<0.05)$. The difference is due to a significantly higher incidence of PIH in twin than in singleton pregnancies, in particular in nulliparous women, whereas the incidence of preeclampsia is not different between twin pregnancies and singleton controls. Severe pre-eclampsia (proteinuria > $5 \mathrm{~g} /$, or HELLP) occurred in eight of 187 women with a twin pregnancy compared with 10 of 187 controls, a non-significant difference. Eclampsia was not observed in either group. The median highest diastolic blood pressure before delivery in the twin pregnancies was 80 $\mathrm{mmHg}$ (range, $55-130 \mathrm{mmHg}$ ), not different from the median highest diastolic blood pressure in the singleton pregnancy group of $80 \mathrm{mmHg}$ (range, $55-150 \mathrm{mmHg}$ ). The incidence of pregnancy-induced hypertensive disorders in certainly dizygotic twin pregnancies $(31 / 134)$ was not different from that in certainly or estimated monozygotic twin pregnancies (11/49). The median interval between the diagnosis of PIH and delivery in twin pregnancy (14 days) was twice that in singleton pregnancy (7 days), but the difference is not statistically different; the same is true for the interval between the diagnosis of pre-eclampsia and delivery in twin (12 days) and singleton (18 days) gestation. The hypertensive disorder was the main indication for termination of pregnancy by induction of labor or cesarean section in 10 twin pregnancies (five $\mathrm{PIH}$, five pre-eclampsia) compared with 11 singleton pregnancies (five $\mathrm{PIH}$, six preeclampsia). The median gestational age at termination of pregnancy for this indication was $37(32-40)$ weeks in twin pregnancies and $34(28-36)$ weeks in singletons $(P$ $<0.05$ ). Birthweight ratios in twin pregnancies complicated by PIH (median, 0.86; range, 0.70-1.02) were 
orders in twin and singleton pregnancies are in general agreement with those obtained in other large series of twin pregnancies and singleton controls $[2,3,8]$. However, the definition of hypertensive disease in pregnancy varies greatly in those reports, in particular with regard to the presence or absence of proteinuria, an important determinant of the severity of the disease and of pregnancy outcome [15]. In our series the higher proportion of hypertensive disease in twin pregnancies is due to pregnancy-induced hypertension, whereas the incidence of proteinuric pre-eclampsia is not different from that in singleton pregnancy. In a population study in Aberdeen MacGillivray [2] found that the incidence of preeclampsia in the first pregnancy was five times greater in twin than in singleton pregnancies. Nylander and MacGillivray [16] examined the incidence of preeclampsia in twin pregnancies in Ibadan and found only $4.5 \%$ in all parities compared with $6 \%$ in singletons. However, when they considered first pregnancies only, the rates were $5.9 \%$ and $1.1 \%$ for twin and singleton pregnancies, respectively. An extremely high incidence of $30 \%$ of proteinuric pre-eclampsia was observed in black African women with twin pregnancy [17]. Part of the differences may be explained by geographical variation in the prevalence of hypertensive disorders, but the majority of reports in the literature cannot be used for international comparison. The elevated incidence of preeclampsia in twin pregnancy in hospital-based studies $[3,8]$ could be due, at least in part, to selection bias, because patients with pre-eclampsia may be more easily referred to a tertiary care center than women with PIH alone. For that reason we included in our study only women who were under our antenatal care before 24 weeks' gestation. Some studies have found a higher incidence of pre-eclampsia in unlike-sex than in like-sex twin pregnancies, which would suggest an immunological cause due to maternal-fetal antigenic differences in dizygotic twin pregnancy [18]. Other studies, however, found higher rates of pre-eclampsia associated with monozygotic as compared with dizygotic twins [17] or no differences [19]. Also, in our study no influence of zygosity on the incidence of pregnancy-induced hypertensive disorders was apparent, but the numbers are relatively small.

A greater proportion of singleton than of twin pregnancies may be expected to continue until term, and so more singleton than twin pregnancies will be at risk of developing a pregnancy-induced hypertensive disorder later in pregnancy. For that reason we matched for gestational age at delivery. However, in twins preterm delivery is often caused by the condition of multiple pregnancy itself, whereas in singleton pregnancies a higher proportion of preterm deliveries may be attributable to induction of labor for a hypertensive disorder. This was indeed observed in our study and would tend to introduce a bias towards a higher incidence of pre-eclampsia in singleton pregnancy with a smaller difference in hypertensive disorders between twins and singletons.

The increased incidence of non-proteinuric PIH in twin pregnancies in our study could be due to the higher cardiac output and circulating plasma volume $[20,21]$ in multiple pregnancies compared with singleton gestations. If we accept that in twin pregnancy cardiac output is increased by heart rate, compared with singleton pregnancy [20], as well as by stroke volume, in particular in the third trimester [21], the occurrence of PIH may be explained by failure to decrease peripheral vascular resistance any further when the physiologic limit for singleton pregnancy has been reached. In that case normal organ perfusion would be maintained, and the endothelial damage associated with reduced perfusion in pre-eclampsia [22] would not be expected to occur. The finding that birthweight ratios in twin pregnancies with PIH were equal to those in normotensive twin pregnancies supports this hypothesis.

There is no doubt that multiple pregnancy is associated with greater risks for both mother and fetuses compared with singleton pregnancy, but our study failed to substantiate an increased risk of proteinuric preeclampsia in a cohort of predominantly white women with twin pregnancies.

\section{References}

[1] Bender S. Twin pregnancy. A review of 472 cases. J Obstet Gynaecol Br Emp 1952; 59: 510-517.

[2] MacGillivray I. Some observations on the incidence of preeclampsia. J Obstet Gynaecol Br Emp 1958; 65, 536-539.

[3] Long PA, Oats JN. Pre-eclampsia in twin pregnancy - severity and pathogenesis. Aust NZ J Obstet Gynaecol 1987; 27(1): 1-5.

[4] Russell JK. Maternal and foetal hazards associated with twin pregnancy. J Obstet Gynaecol Br Emp 1952; 59: 208-213.

[5] Kurtz GR, Keating WF, Loftus JB. Twin pregnancy and delivery. Obstet Gynaecol 1955; 2: 35-41.

[6] Anderson WJR. Stillbirth and neonatal mortality in twin pregnancy. J Obstet Gynaecol Br Emp 1956; 63: 205-215.

[7] Waddell KE, Hunter JS. Twin pregnancies. Am J Obstet Gynecol 1960; 80: 756-760.

[8] McFarlane A, Scott JS. Pre-eclampsia/eclampsia in twin pregnancies. J Med Genet 1976: 13: 208-211.

[9] Collins R, Wallenburg HCS. Pharmacological prevention and treatment of hypertensive disorders in pregnancy. In: Chalmers I, Enkin M, Keirse MJNC, eds. Effective care in pregnancy and childbirth, vol. 1. Oxford: Oxford University Press, 1989; 512-533.

[10] Bremer HA, Wallenburg HCS. Aspirin in pregnancy. Fetal Matern Med Rev 1992; 4: 37-57.

[11] Clasp Collaborative Group. CLASP: a randomised trial of lowdose aspirin for the prevention and treatment of pre-eclampsia among 9364 pregnant women. Lancet 1994; 343: 619-628.

[12] Davey DA, MacGillivray I. The classification and definition of the hypertensive disorders of pregnancy. Am J Obstet Gynecol 1988; 158: 892-898.

[13] Kloosterman GJ. On intrauterine growth. Int J Gynaecol Obstet 1970; 18: 895-912. 
Table 1

Clinical characteristics and outcome of pregnancy in twin and singleton pregnancies

\begin{tabular}{|c|c|c|c|c|c|c|}
\hline & \multicolumn{3}{|c|}{ Twin pregnancy $(n=187)$} & \multicolumn{3}{|c|}{ Singleton pregnancy $(n=187)$} \\
\hline & Median & (range) & $n$ & Median & (range) & $n$ \\
\hline Maternal age (years) & 30 & $(17-47)$ & & 30 & $(17-45)$ & \\
\hline Nulliparous & & & 103 & & & 103 \\
\hline Parous & & & 84 & & & 84 \\
\hline $\begin{array}{l}\text { Gestational age at first antenatal } \\
\text { visit (weeks) }\end{array}$ & 14 & $(6-23)$ & & 13 & $(6-23)$ & \\
\hline $\begin{array}{l}\text { Gestational age at delivery } \\
\text { (weeks) }\end{array}$ & 37 & $(21-41)$ & & 37 & $(21-41)$ & \\
\hline \multicolumn{7}{|l|}{ Mode of delivery } \\
\hline Vaginal & & & 150 & & & 158 \\
\hline Lower segment cesarean section & & & 37 & & & 29 \\
\hline \multicolumn{7}{|l|}{ Birthweights (g) } \\
\hline First born & 2375 & $(140-3715)$ & & 2840 & $(150-4130)$ & \\
\hline Second born & 2338 & $(130-3660)$ & & - & - & \\
\hline \multicolumn{7}{|l|}{ Birthweight ratio } \\
\hline First born & 0.87 & $(0.23-1.58)$ & & 0.97 & $(0.44-1.60$ & \\
\hline Second born & 0.84 & $(0.12-1.23)$ & & - & - & \\
\hline Perinatal mortality $(\%)$ & 58.8 & & & 26.7 & & \\
\hline Fetal deaths & 2 & & & 1 & & \\
\hline Neonatal deaths & 20 & & & 4 & & \\
\hline \multicolumn{7}{|l|}{ Zygosity } \\
\hline Certainly monozygotic & 39 & & & & & \\
\hline Certainly dizygotic & 134 & & & & & \\
\hline Estimated monozygotic & 49 & & & & & \\
\hline
\end{tabular}

not different from those in normotensive twin pregnancies (median, 0.88; range, 0.23-1.58), but somewhat higher than those in twin pregnancies with preeclampsia (median 0.84 , range $0.68-0.98$ ), although the difference was not significant.

The perinatal mortality rate in twins was twice that in singletons $(P<0.05)$ due to a higher number of neonatal deaths associated with lethal congenital abnormalities $(n=2)$ and complications of twin-to-twin transfusion $(n=6)$. In the twin group two of the perinatal deaths occurred in the 11 patients with preeclampsia, whereas one perinatal death occurred in the 12 pre-eclamptic singleton pregnancies.

\section{Discussion}

The results of our matched-pair comparative study on the incidence of all pregnancy-induced hypertensive dis-

Table 2

Incidence of hypertensive disorders in twin and singleton pregnancies

\begin{tabular}{|c|c|c|c|c|c|c|c|c|c|c|c|c|}
\hline & \multicolumn{6}{|c|}{ Twin pregnancy } & \multicolumn{6}{|c|}{ Singleton pregnancy } \\
\hline & \multicolumn{2}{|c|}{$\begin{array}{l}\text { Nulliparous } \\
(n=103)\end{array}$} & \multicolumn{2}{|c|}{$\begin{array}{l}\text { Parous } \\
(n=84)\end{array}$} & \multicolumn{2}{|c|}{$\begin{array}{l}\text { Total } \\
(n=187)\end{array}$} & \multicolumn{2}{|c|}{$\begin{array}{l}\text { Nulliparous } \\
(n=103)\end{array}$} & \multicolumn{2}{|c|}{$\begin{array}{l}\text { Parous } \\
(n=84)\end{array}$} & \multicolumn{2}{|c|}{$\begin{array}{l}\text { Total } \\
(n=187)\end{array}$} \\
\hline & $n$ & $\%$ & $n$ & $\%$ & $n$ & $\%$ & $n$ & $\%$ & $n$ & $\%$ & $n$ & $\%$ \\
\hline Normotensive & 73 & (71) & 72 & (86) & 145 & $(77.6)$ & 85 & $(82)$ & 73 & $(87)$ & 158 & (84.5) \\
\hline Hypertensive & 30 & (29) & 12 & (14) & 42 & $(22.4)^{*}$ & 18 & (18) & 11 & (13) & 29 & $(15.5)$ \\
\hline PIH & 20 & (19) & 8 & $(10)$ & 28 & $(15.0)^{*}$ & 5 & $(5)$ & 7 & (8) & 12 & $(6.4)$ \\
\hline Pre-eclampsia & 7 & (7) & 1 & (1) & 8 & $(4.2)$ & 8 & (8) & 0 & & 8 & $(4.2)$ \\
\hline Pre-eclampsia + HELLP & 2 & (2) & 0 & & 2 & $(1.1)$ & 2 & (2) & 0 & & 2 & (1.1) \\
\hline Chronic hypertension & 1 & (1) & 2 & $(2)$ & 3 & (1.6) & 1 & (1) & 4 & (5) & 5 & $(2.7)$ \\
\hline $\begin{array}{l}\text { Chronic hypertension with } \\
\text { superimposed pre- } \\
\text { eclampsia }\end{array}$ & 0 & & 1 & (1) & 1 & $(0.5)$ & 2 & (2) & 0 & & 2 & (1.1) \\
\hline
\end{tabular}

${ }^{*} P<0.05$ compared with singleton pregnancy 
[14] Weinberg W. Differenzmethode und Geburtenfolge bei Zwillingen. Genetica 1934; 16: 282-288.

[15] Wallenburg HCS. Detecting hypertensive disorders in pregnancy. In: Chalmers I, Enkin M, Keirse MJNC, eds. Effective care in pregnancy and childbirth, vol. 1. Oxford: Oxford University Press, 1989; 382-402.

[16] Nylander PP, MacGillivray I. Complications of twin pregnancy. In: Human multiple reproduction. London: WB Saunders, 1969; 137-146.

[17] McMullan PF, Norman RJ, Marivate M. Pregnancy-induced hypertension in twin pregnancy. Br J Obstet Gynaecol 1984; 91 : 240-243.

[18] Stevenson AC, Davidson BCC, Say B et al. Contribution of fetal/maternal incompatibility to aetiology of pre-eclamptic toxaemia. Lancet 1971; ii: 1286-1289.

[19] Campbell DM, McGillivray I, Thompson B. Twin zygosity and pre-eclampsia. Lancet 1977; ii: 97.

[20] Robson SC, Hunter S, Boys RJ, Dunlop W. Hemodynamic changes during twin pregnancy. A Doppler and M-mode echocardiographic study. Am J Obstet Gynecol 1989; 161: 1273-1278.

[21] Veille JC, Morton MJ, Burry KJ. Maternal cardiovascular adaptations to twin pregnancy. Am J Obstet Gynecol 1985; 153: 261-263.

[22] Roberts JM, Redman CWG. Pre-eclampsia: more than pregnancy-induced hypertension. Lancet $1993 ; 341$ : 1447-1454. 